\title{
Vernacular dominance in folk taxonomy: a case study of ethnospecies in medicinal plant trade in Tanzania
}

\author{
Joseph Otieno ${ }^{1}$, Siri Abihudi ${ }^{1}$, Sarina Veldman², Michael Nahashon ${ }^{2}$, Tinde van Andel ${ }^{3}$ and Hugo J de Boer ${ }^{2,3,4^{*}}$
}

\begin{abstract}
Background: Medicinal plants are traded as products with vernacular names, but these folk taxonomies do not always correspond one-to-one with scientific plant names. These local species entities can be defined as ethnospecies and can match, under-differentiate or over-differentiate as compared to scientific species. Identification of plant species in trade is further complicated by the processed state of the product, substitution and adulteration. In countries like Tanzania, an additional dimension to mapping folk taxonomies on scientific names is added by the multitude of ethnicities and languages of the plant collectors, traders and consumers. This study aims to elucidate the relations between the most common vernacular names and the ethnicity of the individual traders among the medicinal plant markets in Dar es Salaam and Tanga regions in Tanzania, with the aim of understanding the dynamics of vernacular names in plant trade.
\end{abstract}

Methods: A total of 90 respondents were interviewed in local markets using semi-structured interviews. The ethnicity of each respondent was recorded, as well as the language of each ethnospecies mentioned during the interviews. Voucher collections and reference literature were used to match ethnospecies across languages.

Results: At each market, the language of the majority of the vendors dominates the names for medicinal products. The dominant vendors often represent the major ethnic groups of that region. Independent of their ethnicity, vendors offer their products in the dominant language of the specific region without apparently leading to any confusion or species mismatching.

Conclusions: Middlemen, traders and vendors adapt their folk classifications to those of the ethnic groups of the region where they conduct their trade, and to the ethnicity of their main customers. The names in the language of the traders are not forgotten, but relegated in favor of the more salient names of the dominant tribe.

Keywords: Vernacular names, Medicinal plants, Wildlife trade, Tanzania, Sub-Saharan Africa, Traditional medicine, Folk taxonomy

\section{Background}

In Africa, traditional healers and remedies made from plants play an important role in healthcare for millions of people [1,2]. The often-quoted World Health Organization estimate that up to $80 \%$ of population depends on traditional medicine for their primary healthcare [3], is particularly apt for Tanzania where traditional medicine is

\footnotetext{
*Correspondence: hugo.deboer@ebc.uu.se

${ }^{2}$ Department of Organismal Biology, Evolutionary Biology Centre, Uppsala University, Norbyvägen 18D, SE-75236 Uppsala, Sweden

${ }^{3}$ Naturalis Biodiversity Center, Darwinweg 4, Postbus 9517, 2300 RA Leiden, The Netherlands

Full list of author information is available at the end of the article
}

a thriving trade in both rural and urban areas [4-8]. An estimated 5400 plant species are used in traditional medicine in Africa [9]. Estimates of the number of species used in Tanzania vary from 405 [10] to 1100 [11], although many authors agree that too little is currently known $[6,12]$.

Studying medicinal plants traded in markets has been used to quantify the commercialization and utilization of natural products, as these mirror a region's culture, and can give a rapid insight into traditions, salient health problems and the importance of herbal medicine in local health care [13-21]. In addition, surveys of traded medicinal 
products can reveal the diversity and prevalence of these items $[14,15]$ and can help to estimate the total traded species richness $[16,17,20,21]$. Nevertheless, some parts of the local pharmacopeia may be overlooked, and it has been asserted that species entering commercial trade represent a 'short-list' of a far greater diversity of species used for subsistence in rural areas [13].

The rich floral biodiversity of Tanzania with over 11,000 species [22], the estimated number of 5400 species used in traditional medicine in Africa [9], and species diversity in markets in South Africa [14], Benin [20], Gabon [23], Ghana [21] and Morocco [18] suggest that between 200-800 species could be traded in Tanzania. However, published structured quantitative research on medicinal plant trade in the markets of Tanzania is so far lacking, and less than 200 plant species have been documented from trade [12,24-27]. The two main cities trading wild-crafted medicinal plant products in Tanzania are Dar es Salaam with approximately 70 vendors, and Tanga with ca. 50 vendors $[24,25,28]$, but the actual numbers are probably significantly higher. Commercial trade is said to be one of the largest threats to wild medicinal plant populations in Tanzania [24], and vendors in both markets have reported the coastal districts, as well as the Uluguru and Usambara mountains, as the main sources of plant material [24]. The main sources of wild-crafted medicinals coincide with the locations of some of the most threatened biodiversity hotspots in Africa: the Coastal Forest of Eastern Africa and Eastern Afro-montane hotspots [29].

If Tanzania is to provide a sustainable supply of herbal medicine in the future, it needs to know which species are in danger of being overexploited. Knowing the medicinal plant species in trade is a prerequisite for developing a system of controlled sustainable exploitation. Priority species for conservation would be those that are wildharvested in large quantities from vulnerable habitats and reported to be increasingly difficult to obtain. Identification of medicinal plants in trade is complicated, as most material is traded in dried, shredded or powdered form $[7,25,30]$.

Medicinal plants are traded as products with local names in folk taxonomies [31]. These local species entities can be defined as ethnospecies and can match, underdifferentiate or over-differentiate as compared to scientific species. Under-differentiation in ethnospecies is the case when names are being applied to entire genera or unrelated species [13,31], while over-differentiating happens beyond the scientific species level to distinguish intraspecific morphological or pharmacological characters, such as shape, colour and taste [32]. Even hallucinogenic experiences resulting from taking certain medicinal plants are used as properties for over-differentiation of plant species [33]. Other processes that complicate matching ethnospecies and scientific names of products in trade are substitution and adulteration. Adulteration is the intentional replacement of the intended species for another, while substitution is more broadly defined and can include slow general substitution of one species for another due to overharvesting and depletion of the original species $[18,30]$. Substitution and adulteration are not only challenging for scholars of folk taxonomies, but can also be confusing for traders [19] and customers [30]. In Tanzania, as elsewhere in Africa, an additional dimension to mapping folk taxonomies on scientific names is added by the multitude of ethnicities and languages of the plant collectors, traders and consumers [34,35].

This study aims to elucidate the origins of the vernacular names used for the most common ethnospecies in the Tanzanian medicinal plant trade. Our null hypothesis was that traders use the vernacular names in their own language for the ethnospecies they trade, while our alternative hypothesis was that traders adjust the names to those of the dominant group in the area in which they trade. The following research questions are posed: 1 ) What are the ethnicities of medicinal plant traders in Dar es Salaam and Tanga?; 2) What names do the traders use for the products in their stalls?; 3) What are the most likely scientific names for each of the ethnospecies?; 4) Which vernacular name(s) are dominant per ethnospecies?; and 5) What language dominates the medicinal plant trade and why?

\section{Methods \\ Study area}

The study was carried out in Dar es Salaam and Tanga regions from August 2013 to mid-April 2014. Dar es Salaam city and Tanga town are the main hubs of the medicinal plant trade in Tanzania $[7,25,28]$. Plant materials are supplied to here from the surrounding regions of Arusha, Iringa, Lindi, Manyara, Morogoro, and Pwani. These regions include two biodiversity hotspots that are recognized internationally for their high species diversity and endemicity-the Coastal Forests of East Africa and the Eastern Afromontane Forests [29], which are important sources of commercially-traded medicinal plants [7]. These coastal trade cities are melting pots of ethnicity, culture and religion $[7,36]$.

\section{Market survey}

The survey focused on the main areas of medicinal plant trade of Dar es Salaam city and Tanga town, these included Kariakoo market in Dar es Salaam and various streets in Tanga town. In these areas traders are specialized in medicinal plant trade and these businesses rely solely on its commerce. Additional vendors, traditional healers and herbal specialists were surveyed in their shops in other markets, sitting along high traffic thorough 
ways, and walking around the bus stations, traffic intersections and ferry terminals peddling their medicinals. Most vendors stock their supplies crudely on shelves, tables, the ground, cloths or plastic tarps, while others offer processed mixtures in bottles, vials and plastic containers. A total of 90 respondents were interviewed in local markets using semi-structured interviews. The ethnicity of each respondent was recorded, as well as the language of each ethnospecies mentioned during the interviews.

The interview questionnaires were submitted to the Muhimbili University of Health and Allied Sciences (MUHAS), but no ethical review committee permission was needed. All participating vendors of medicinal plants were informed of the objectives of our research project prior to commencement of the interviews, and those that agreed to participate were interviewed.

\section{Botanical collections and identification}

Voucher collections were collected and stored at the herbarium of the Institute for Traditional Medicine, Muhimbili University of Health and Allied Sciences. Botanists from the Muhimbili University of Health and Allied Sciences, Dar es Salaam University and National Herbarium of Tanzania aided in identifying the voucher samples. Specific collection trips were organized with willing traders and collectors to find botanical vouchers if identifications of the vouchers were ambiguous. Reference literature was used to match ethnospecies across languages [28].

\section{Data analysis}

Spreadsheets of respondent data from each interview were compiled into a master table to identify and sort matching species and enumerate the frequency that each species was mentioned. After matching vernacular names and orthographic variation, a total of 207 ethnospecies were identified, of which 124 could be matched with scientific names. The remaining 83 ethnospecies were unidentifiable using either morphology-based identification or vernacular name-guided morphology-based identification. A total of 305 medicinal products were collected as vouchers, including 222 single-ingredient products and 83 multispecies mixtures. Ethnospecies that were reported by 10 or more respondents (19 in total) were analyzed to study vernacular dominance. All ethnospecies were scored by the language in which they were reported during the interview, and could either match the ethnicity of the informant (score 1 in Additional file 1) or differ (score 0 in Additional file 1).

\section{Results}

A total of 90 vendors were interviewed: 79 in Dar es Salaam and 11 in Tanga. Respondents belonged to 18 ethnicities or groups and originated from 17 out of Tanzania's 22 mainland regions (Table 1). A total of 124 species were identified from 207 reported ethnospecies. The data included 305 vouchered products, including 222 single ingredients and 83 mixtures. These vouchers could include a number of redundancies due to vernacular names in different languages. DNA barcoding of these unknowns could enable identification $[18,19,37]$, but this remains to be done.

Results for the 19 most salient ethnospecies were summarized in pie charts per species, including one figure showing the number of matching and non-matching names, one figure showing the language of the matching names and one figure showing the language of the non-matching names (Additional file 2). The totals are presented in Table 2 and show that the vast majority of vendors (80.7\%) use names that match between their ethnicity and language. Among this group of matching names, $88.7 \%$ are Pwani names from the coastal inhabitants including the Dar es Salaam region, and the second largest group are Masaai names, 9.2\%, a group known for their strong cultural identity. Pwani

Table 1 Ethnicity and origin of herbal vendor informants

\begin{tabular}{|c|c|c|c|}
\hline Reported & Ethnologue $^{1}$ & Region & $\begin{array}{l}\text { Number of } \\
\text { informants }\end{array}$ \\
\hline Bushaidi & * & Zanzibar & 1 \\
\hline Digo & Digo & Tanga & 1 \\
\hline Hehe & Hehe & $\begin{array}{l}\text { Iringa; Morogora; } \\
\text { Dodoma; Mbeya }\end{array}$ & 1 \\
\hline Kwere & Kwere & Pwani; Morogoro & 37 \\
\hline Maasai & Maasai & $\begin{array}{l}\text { Arusha; Tanga; } \\
\text { Kilimanjaro; Manyara }\end{array}$ & 17 \\
\hline Mwera & Mwera & Lindi & 1 \\
\hline Ndengereko & Ndengereko & Pwani; Morogoro & 1 \\
\hline Ngunya & * & Zanzibar & 2 \\
\hline Nyaturu & Nyaturu & Singida & 1 \\
\hline Nyiramba & Nilamba & Singida & 1 \\
\hline Pangwa & Pangwa & Iringa & 1 \\
\hline Rangi & Langi & Dodoma & 2 \\
\hline Sambaa & Shambala & Tanga & 11 \\
\hline Segeju & Segeju & Tanga & 1 \\
\hline Shirazi & * & Zanzibar & 1 \\
\hline Sukuma & Sukuma & $\begin{array}{l}\text { Shinyanga; Mwanza; } \\
\text { Kagera; Tabora; Singida; } \\
\text { Kigoma; Mara }\end{array}$ & 1 \\
\hline Zaramo & Zaramo & Pwani & 8 \\
\hline \multirow[t]{2}{*}{ Zigua } & Zigula & Tanga; Pwani; Manyara & 2 \\
\hline & & $\begin{array}{l}\text { Total number } \\
\text { of informants }\end{array}$ & 90 \\
\hline
\end{tabular}

${ }^{1}$ Ethnologue. Languages of the World. http://www.ethnologue.com/ *Groups from Zanzibar not present in Ethnologue. 
Table 2 Cumulative totals of reported language for the 19 most common ethnospecies

\begin{tabular}{lrrlrr}
\hline Language & $\#$ & $\%$ & Language & $\#$ & $\mathbf{\%}$ \\
\hline Matching & $\mathbf{2 8 4}$ & $\mathbf{8 0 , 7}$ & Non-matching & $\mathbf{6 8}$ & $\mathbf{1 9 , 3}$ \\
Pwani & 252 & 88,7 & Pwani & 49 & 72,1 \\
Zigua & 5 & 1,8 & Zigua & 5 & 7,4 \\
Pare & 0 & 0 & Pare & 1 & 1,5 \\
Masaai & 26 & 9,2 & Masaai & 8 & 11,8 \\
Kwere & 0 & 0 & Kwere & 1 & 1,5 \\
Sambaa & 1 & 0,4 & Sambaa & 0 & 0 \\
Makonde & 0 & 0 & Makonde & 4 & 5,9 \\
\hline
\end{tabular}

Left columns (Matching) show the frequencies and percentages of species that were reported in the same language as the ethnicity of the vendor. Right columns (Non-matching) show the frequency and percentages of species that were reported in a language not matching the ethnicity of the vendor and the language in which the species was reported in those cases.

names are used by the Kwere and Zaramo, and sometimes also by the Zigua (Tables 3 and 1). Among the nonmatching names, the Pwani names are predominant with $72.1 \%$, followed by Masaai $11.1 \%$, Zigua $7.4 \%$, Makonde $5.9 \%$, Pare $1.5 \%$ and Kwere $1.5 \%$.

\section{Discussion}

The ethnicities of the medicinal plant vendors were very diverse and reflected the ethnic diversity of Tanzania (Table 1). Many of the vendors in Dar es Salaam belong to Pwani groups, Kwere, Zaramo and Zigua (47 out of 79). In Tanga most vendors belong to the Sambaa tribe (8 of 11). In an earlier study from Tanzania, McMillen [7] discussed the difficulties in reducing ethnospecies in multiple languages (Shambaa, Maasai, Zigua and Digo), but the author focused on a limited number of species to study evolution and transmission of ethnobotanical knowledge. In both cities the principal ethnic groups in the regions were prominent among the vendors. Vendors routinely identified ethnospecies with vernacular names in their languages, but when they did not, they used the languages of the predominant groups in both cities. Many vendors knew also the name of the ethnospecies in other languages, such as their own or that of other groups. Our data show that the dominant language in which ethnospecies are reported in the Dar es Salaam and Tanga markets combined are the languages spoken in Pwani region. Nevertheless, $72.1 \%$ of vernacular names that were reported in languages that did not match the ethnicity of the vendor were reported in Pwani.

The latter language dominance could either be an artifact of interviewing in a non-native language, Kiswahili in this study, or it could show that vendors are adapting the vernacular names of the products to the mainstream cultures in these cities. Such adaptation makes sense in a market economy where instant recognition of products by passing customers is essential to securing a sale. Numerous products are packed in striking packets and other products in the market are promoted using easy to recognize names, e.g. One Plus, Extra Power or any common Swahili name not limited to a particular ethnicity such as Hakika, Bingwa, etc. Unique packaging of herbal material is a monopoly strategy in which the ownership of a product in the public domain is bound to the vendor, but without necessarily providing any added value. Packaging can however lead to concealment of the original ethnospecies.

Other aspects of folk taxonomy that are highly relevant in the discussion of this study are monotypic versus polytypic folk generics sensu Berlin [31], descriptive names and globalized plant names. Generally folk classifications have an excess of monotypic taxa, but vernacular names reported in the market could be folk generics with unreported polytypic diversity. These folk generics could constitute a number of species that are related either within the same genus or based on characteristics significant for its folk classification. Plant medicinals traded as bark, roots or powder can pose specific challenges in uncovering polytypic taxa, but DNA barcoding is transforming this and helping to uncover cryptic diversity in folk classifications [18,19,38]. Among the reported data we expect polytypic folk generics in important savannah and miombo woodland genera, Acacia, Brachystegia, Isoberlinia, Julbernardia, and Zanthoxylum, but this remains to be tested. Descriptive names are common in folk taxonomies and influence oral knowledge transmission [39]. Many descriptive names are mnemonics and confer information on the traditional use or perceived properties [39]. Leonti et al. [40] show that two ethnic groups in Mexico that have split from common ancestors over 2000 years ago share cognate plant names in their pharmacopoeias. Van Andel et al. [41] show that among Maroons in Suriname, descendants of escaped slaves, more than $40 \%$ of the vernaculars have strong resemblance in sound, structure, and meaning to African plant names for related taxa. The paper shows that Africans recognized substantial parts of the American flora, and applied their mnemonics to this new flora. In this study some of the local names are descriptive, and adoption of descriptive names from the dominant Pwani language probably helps communicating medicinals in the multiethnic reality of the medicinal plant market. In some cases local names are dropped completely in favor of globalized plant names, e.g. Echinacea, Ginseng and Ginkgo are names found in trade around the world. In Tanzania, where trade relies mainly on locally sourced plants this is only observed for Aloe spp., and these are often traded using the folk generic aloevera irrespective of the specific species or provenance.

Adaptive nomenclature and acculturation are ingrained aspects of a free market economy, but there are drawbacks with apparent risks associated to compromising one's own 
Table 3 Scientific names and dominant vernacular names of the studied species*

\begin{tabular}{|c|c|c|c|}
\hline Scientific name & Family & Dominant vernacular name (language region) & Voucher No. $^{5}$ \\
\hline Acacia nilotica (L.) Willd. & Fabaceae & Ol kiloriti (Masaai) & SA 24 \\
\hline Acalypha ornata Hochst. ex A.Rich. & Euphorbiaceae & Mfulwe (Pwani) & SA 39 \\
\hline Afzelia quanzensis Welw. & Fabaceae & Mkongo (Pwani) & SA 45 \\
\hline Albizia anthelmintica Brongn. & Fabaceae & Mfuleta (Pwani) & SA 19 \\
\hline Bonamia mossambicensis (Klotzsch) Hallier $\mathrm{f}$. & Convolvulaceae & Mlipu (Pwani) & SA 20 \\
\hline Cassia abbreviata Oliv. & Fabaceae & Mkundekunde (Pwani) & SA 14 \\
\hline Combretum fragrans F.Hoffm. & Combretaceae & Mlama (Pwani) & SA 48 \\
\hline Diospyros zombensis (B.L.Burtt) F.White & Ebenaceae & Kasela (Pwani) & SA 41 \\
\hline Holarrhena febrifuga Klotzsch & Apocynaceae & Mmelemele (Pwani) & SA 18 \\
\hline Hymenaea verrucosa Gaertn. & Fabaceae & Mkumbi (Pwani) & SA 30 \\
\hline Keetia venosa (Oliv.) Bridson & Rubiaceae & Mkandachuma (Pwani) & SA 47 \\
\hline Rapanea melanophloeos (L.) Mez & Myrsinaceae & Mpaja (Pwani) & SA 42 \\
\hline Sclerocarya birrea (A.Rich.) Hochst. & Anacardiaceae & Mngo'ng'o (Pwani) & SA 38 \\
\hline Suregada zanzibariensis Baill. & Euphorbiaceae & Mdimu mpori (Pwani) & SA 40 \\
\hline Uvaria acrantha Miq. & Annonaceae & Msofu (Pwani) & SA 33 \\
\hline Warburgia elongata Verdc. & Canellaceae & Mwifu (Pwani) & SA 46 \\
\hline Ximenia aegyptiaca L. & Olacaceae & Mpingi (Pwani) & SA 37 \\
\hline Zanha africana (Radlk.) Exell & Sapindaceae & Mdaula (Pwani) & SA 06 \\
\hline Zanthoxylum chalybeum Engl. & Rutaceae & Mjafari (Pwani) & SA 26 \\
\hline
\end{tabular}

*Species that were reported by 10 or more respondents. ${ }^{\$}$ All vouchers are deposited at the herbarium of the Institute for Traditional Medicine, Muhimbili University of Health and Allied Sciences.

ethnic indigenous knowledge for the sake of business. An example from Mexico shows that acculturation synchronizes elements from the socio-economically dominant culture by substituting similar components in the subjected society, i.e. leading to a systemic substitution of native idiom for loanwords [42]. Consequently, the peculiarities and identity of the minorities gradually diminish without proper or structured documentation.

Direct economic incentive as observed here as a driver for knowledge erosion has not been documented previously, but rapid decline of traditional culture under the influence of dominant cultures has been widely documented. Benz et al. [43] found that plant use knowledge loss among people in the Sierra de Manantlan Biosphere Reserve in Mexico was related dominant language use, i.e. people speaking the Huastec indigenous language had a more diverse and evenly shared plant knowledge than people having adopted the majority mestizo and Spanish language. Sharma et al. [44] similarly found a rapid erosion of herbal traditions among the Hajong communities in India linked to language loss. Srithi et al. [45] documented an inter-generational loss of traditional plant knowledge by Mien ethnic communities in Northern Thailand due to acculturation and interrupted knowledge transmission.

Although this study set out to seek the dominant ethnicities in the Tanzanian herbal medicine market, the interviews showed the contribution of the ethnic and cultural diversity in the current development of the traditional medicine market. Importantly, Dar es Salaam is a cosmopolitan city attracting myriads of vendors from rural areas intending to penetrate and subsist in the Pwani market. At the same time, it does not tax the vendor to relinquish their language and cultural identity by embracing the prominent market names. Tanzania is characterized by social tranquility and communities tend not to be divided by ethnic lines. However, emphasis should now be put on the necessity of proper documentation of the knowledge of the minority ethnicities that operate on the verge of contemporary market networks.

The observation of adaptation of plant names contrasts with other studies in Africa that show that vendors use vernacular names from their own language, and that their clientele often belong to their own ethnic group $[20,21,23]$. In Gabon, Towns et al. [23] found that Beninese immigrants have their own stalls, trade plants imported from Benin, using Beninese vernacular names, and sell their goods to Beninese migrant clients. In Ghana, Hausa traders were found to be selling plants with Hausa names to their Hausa clients, while Twi-speaking traders sold the same plants with Twi names to Akan people [21]. In Accra, Hausa people go to a specific market with many northern people, while Twi speaking people go to another market in the same city with Twi speaking traders [21]. In Benin, Fon, 
Yoruba, Dendi and Bariba traders marketed plant products in their own languages, yet in the same study it was observed that Fon and Yoruba vernacular names were mentioned even when the vendors were of different ethnicities [20]. The latter pattern is similar to that observed in this study, and reflects the need of migrant vendors to adapt their traditional names into the commercial names of the dominant ethnic group to augment trade.

\section{Conclusions}

Knowing what species are traded commercially is the foundation for identifying threatened taxa and comparing regional and national medicinal markets, but identification of plant products in marketplaces poses challenges to monitoring commercialization of biodiversity. Rich vernacular heterogeneity due to ethnic diversity adds a level of complexion to plant identification, but this is mitigated by vernacular dominance of the predominant groups in the market towns. African cosmopolitan cities like Dar es Salaam attract people from rural areas and broadly reflect the country's ethnic diversity. Rural entrepreneurs entering the herbal medicine trade adapt their nomenclature to optimize trade, and this malleability is observed in the variety of names of traded medicinals. However, some vendors also maintain local vernacular names, and this could reflect safeguarding cultural identity. Studying and documenting the knowledge of minority ethnicities that operate on the verge of contemporary market networks can provide valuable insights that are missed when focusing on mainstream culture and main market centers.

\section{Additional files}

Additional file 1: Data S1 Master table.

Additional file 2: Data S2 Charts.

\section{Competing interests}

The authors declare that they have no competing interests.

\section{Authors' contributions}

JO, SV and HdB conceived the research. SA, SV, and JO were responsible for field research and interviews. JO and SA identified the herbarium vouchers; $\mathrm{HdB}, \mathrm{SV}, \mathrm{SA}$ and $\mathrm{JO}$ processed the data. SA, JO, MN, TVA and HdB contributed to the manuscript. All authors have read and approved the final manuscript.

\section{Acknowledgements \\ We thank the vendors of medicinal plants that participated in this study for sharing their knowledge. This research was carried out as part of the COSTECH-NWO-SIDA TASENE collaboration (W 02.29.102) "Identifying and monitoring trade in Tanzanian wild-harvested medicinal plants by means of innovative genomics-based DNA barcoding". Additional support is acknowledged from SIDA Minor Field Study grants (MN), the Nordic Africa Institute (MN) and the Society for Economic Botany's Richard E. Schultes Award (HdB).}

\section{Author details}

${ }^{1}$ Institute of Traditional Medicine, Muhimbili University of Health and Allied Sciences, P.O. Box 65001, Dar es Salaam, Tanzania. ²Department of Organismal Biology, Evolutionary Biology Centre, Uppsala University, Norbyvägen 18D, SE-75236 Uppsala, Sweden. ${ }^{3}$ Naturalis Biodiversity Center,
Darwinweg 4, Postbus 9517, 2300 RA Leiden, The Netherlands. ${ }^{4} T$ The Natural History Museum, University of Oslo, P.O. Box 1172, NO-0318 Oslo, Norway.

Received: 21 October 2014 Accepted: 10 December 2014 Published: 19 February 2015

\section{References}

1. Cunningham AB. African medicinal plants: setting priorities at the interface between conservation and primary health care. People Plants Work Pap. 1993;1:1-50

2. De Boer HJ. African plants as antipathogen agents: Clinical and experimental evidence. In: Watson R, Preedy V, editors. The Encyclopedia of Herbal Medicine in Clinical Practice. Wallingford: CABI publishing; 2009.

3. World Health Organization. Traditional Medicine. Factsheet No. 134. 2003.

4. Otieno JN, Kajembe GC, Malimbwi R, Nduwamungu J. The contribution of herbal medicine to the welfare of local communities: a case of babati district, Tanzania. Tanzan J Popul Stud Dev. 2001;8:1-10.

5. Otieno JN, Lyaruu HVM, Hosea KMM. Ethnobotany and indigenous use of medicinal plants for life support among local communities in Lake Victoria basin, Tarime District, Tanzania. Tanzania Tanzan J Popul Stud Dev. 2006;13:1-14.

6. De Boer HJ, Kool A, Broberg A, Mziray WR, Hedberg I, Levenfors JJ. Anti-fungal and anti-bacterial activity of some herbal remedies from Tanzania. J Ethnopharmacol. 2005:96:461-9.

7. McMillen $\mathrm{H}$. Ethnobotanical knowledge transmission and evolution: the case of medicinal markets in tanga, Tanzania. Econ Bot. 2012;66:121-31.

8. Stangeland T, Dhillion SS, Reksten H. Recognition and development of traditional medicine in Tanzania. J Ethnopharmacol. 2008;117:290-9.

9. Neuwinger HD. African Traditional Medicine: A Dictionary of Plant Use and Applications. .: Medpharm Scientific Publishers Pretoria; 2000.

10. Chhabra SC, Mahunnah RLA, Mshiu EN. Plants used in traditional medicine in Eastern Tanzania. VI. Angiosperms (Sapotaceae to Zingiberaceae). J Ethnopharmacol. 1993:39:83-103.

11. Pergola T. Changes in Using and Conserving Medicinal Plants in Maasai Villages in Monduli District, Tanzania. Arusha, Tanzania: Terrawatu; 2003.

12. Hedberg I, Hedberg O, Madati PJ, Mshigeni KE, Mshiu EN, Samuelsson G. Inventory of plants used in traditional medicine in Tanzania. I. Plants of the families Acanthaceae-Cucurbitaceae. J Ethnopharmacol. 1982;6:29-60.

13. Cunningham AB. Applied Ethnobotany: People, Wild Plant Use and Conservation. Volume 4. .: Earthscan/James \& James; 2001.

14. Williams VL. Hawkers of health: an investigation of the Faraday Street traditional medicine market in Johannesburg, Gauteng. Final Report to the Gauteng Directorate of Nature Conservation, DACEL. Plant Ecol Conserv Ser. 2003;15

15. Bussmann RW, Sharon D, Vandebroek I, Jones A, Revene Z. Health for sale: the medicinal plant markets in Trujillo and Chiclayo. Northern Peru J Ethnobiol Ethnomedicine. 2007;3:37.

16. Van Andel TR, Behari-Ramdas J, Havinga R, Groenendijk S. The medicinal plant trade in Suriname. Ethnobot Res Appl. 2008;5:351-72.

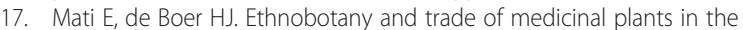
Qaysari Market, Kurdish Autonomous Region, Iraq. J Ethnopharmacol. 2011;133:490-510.

18. Kool A, de Boer HJ, Krüger Å, Rydberg A, Abbad A, Björk L, et al. Molecular identification of commercialized medicinal plants in Southern Morocco. PLoS One. 2012;7:e39459.

19. De Boer HJ, Ouarghidi A, Martin G, Abbad A, Kool A. DNA barcoding reveals limited accuracy of identifications based on folk taxonomy. PLoS One. 2014;9:e84291.

20. Quiroz D, Towns A, Legba SI, Swier J, Brière S, Sosef M, et al. Quantifying the domestic market in herbal medicine in Benin, West Africa. J Ethnopharmacol. 2014:151:1100-8

21. Van Andel T, Myren B, van Onselen S. Ghana's herbal market. J Ethnopharmacol. 2012;140:368-78

22. Mahunnah RLA, Mshigeni KE. Tanzania's policy on biodiversity prospecting and drug discovery programs. J Ethnopharmacol. 1996;51:221-8.

23. Towns AM, Quiroz D, Guinee L, de Boer H, van Andel T. Volume, value and floristic diversity of Gabon's medicinal plant markets. J Ethnopharmacol. 2014;155:1184-93.

24. Marshall NT. Searching for a Cure: Conservation of Medicinal Wildlife Resources in East and Southern Africa. Nairobi, Kenya: TRAFFIC East Africa; 1998. 
25. McMillen HL. Conserving the Roots of Trade: Local Ecological Knowledge of Ethnomedicines from Tanga, Tanzania Markets. 2008.

26. Hedberg I, Hedberg O, Madat PJ, Mshigeni KE, Mshiu EN, Samuelsson G. Inventory of plants used in traditional medicine in Tanzania. II. Plants of the families Dilleniaceae-Opiliaceae. J Ethnopharmacol. 1983;9:105-27.

27. Hedberg I, Hedberg O, Madati PJ, Mshigeni KE, Mshiu EN, Samuelsson G. Inventory of plants used in traditional medicine in Tanzania. Part III. Plants of the families Papilionaceaevitaceae. J Ethnopharmacol. 1983;9:237-60.

28. Nahashon M. Conservation of Wild-harvested Medicinal Plant Species in Tanzania: Chain and consequence of commercial trade on medicinal plant species. Uppsala University: MSc thesis; 2013.

29. Myers N, Mittermeier RA, Mittermeier CG, da Fonseca GA, Kent J. Biodiversity hotspots for conservation priorities. Nature. 2000;403:853-8.

30. Ouarghidi A, Powell B, Martin GJ, de Boer HJ, Abbad A. Species substitution in medicinal roots and possible implications for toxicity in Morocco. Econ Bot. 2012;66:370-82.

31. Berlin B. Ethnobiological Classification: Principles of Categorization of Plants and Animals in Traditional Societies. NJ: Princeton University Press Princeton; 1992.

32. Reijers M. African heritage in Maroon agriculture: Multiple uses of Old World crops among Aucans and Saramaccans. Wageningen University and Research: MSc thesis; 2014.

33. Schultes RE, Raffauf RF. Vine of the Soul: Medicine Men, Their Plants and Rituals in the Colombian Amazonia. Santa Fe, USA: Synergetic Press Inc.; 1992.

34. Lewis MP. Ethnologue: Languages of the World. 16th ed. Dallas, TX: SIL International; 2009. Online version: http://www.ethnologue.com

35. Muzale HR, Rugemalira JM. Researching and Documenting the Languages of Tanzania. 2008.

36. Obrist B. Struggling for Health in the City: An Anthropological Inquiry of Health, Vulnerability and Resilience in Dar Es Salaam. Tanzania: Peter Lang; 2006.

37. Veldman S, Otieno J, Gravendeel B, van Andel T, de Boer H. Conservation of Endangered Wild Harvested Medicinal Plants: use of DNA Barcoding. Nov Plant Bioresour Appl Food Med Cosmet. 2014;::81-8.

38. Ragupathy $\mathrm{S}$, Newmaster SG, Murugesan M, Balasubramaniam V. DNA barcoding discriminates a new cryptic grass species revealed in an ethnobotany study by the hill tribes of the Western Ghats in southern India. Mol Ecol Resour. 2009;9:164-71.

39. Bennett BC. Doctrine of signatures: an explanation of medicinal plant discovery or dissemination of knowledge? Econ Bot. 2007:61:246-55.

40. Leonti M, Sticher O, Heinrich M. Antiquity of medicinal plant usage in two macro-Mayan ethnic groups (Mexico). J Ethnopharmacol. 2003;88:119-24.

41. Van Andel TR, Van't Klooster Cl, Quiroz D, Towns AM, Ruysschaert S, van den Berg M. Local plant names reveal that enslaved Africans recognized substantial parts of the New World flora. Proc Natl Acad Sci. 2014;Early Edition:201418836

42. Bye R, Linares E, Estrada E. Biological diversity of medicinal plants in Mexico. In Phytochem Med Plants Springer. 1995;:.65-82.

43. Benz BF, Cevallos JE, Santana FM, Rosales JA, Graf SM. Losing knowledge about plant use in the Sierra de Manantlan biosphere reserve, Mexico. Econ Bot. 2000;54:183-91.

44. Sharma UK, Pegu S, Hazarika D, Das A. Medico-religious plants used by the Hajong community of Assam, India. J Ethnopharmacol. 2012;143:787-800.

45. Srithi $\mathrm{K}$, Balslev H, Wangpakapattanawong P, Srisanga P, Trisonthi C. Medicinal plant knowledge and its erosion among the Mien (Yao) in northern Thailand. J Ethnopharmacol. 2009:123:335-42.

doi:10.1186/1746-4269-11-10

Cite this article as: Otieno et al.: Vernacular dominance in folk taxonomy: a case study of ethnospecies in medicinal plant trade in Tanzania. Journal of Ethnobiology and Ethnomedicine 2015 11:10.

\section{Submit your next manuscript to BioMed Central and take full advantage of:}

- Convenient online submission

- Thorough peer review

- No space constraints or color figure charges

- Immediate publication on acceptance

- Inclusion in PubMed, CAS, Scopus and Google Scholar

- Research which is freely available for redistribution

Submit your manuscript at www.biomedcentral.com/submit 